\title{
PENGARUH KINERJA PELAYANAN DENGAN PENDEKATAN MALCOLM BALDRIGE TERHADAP KEPUASAN PASIEN BPJS KESEHATAN PADA RUMAH SAKIT UMUM DAERAH KOTA BATAM
}

\author{
Heryenzus, Suali \\ Universitas Putera Batam \\ e-mail: heryenzus@gmail.com
}

\begin{abstract}
The hospital is a form of organization engaged in health services. This health service is always demanded to always improve. This is not easy, because there is increasing competition. One of the key success factors in improving organizational performance begins with the patient's own patient satisfaction. This study uses the Malcolm Baldrige Criteria for Performance Excellence (MBCfPE) criteria. MBCfPE is one method of improving organizational performance as a whole and continuously.MBCfPE.As for the purpose of this research is to test and analyze the effect of each of the six MBCFPE criteria (leadership, strategic planning, focus on customers, measurement, analysis and management knowledge, focus on employees, process management.) on BPJS health patient satisfaction at Batam Regional General Hospital. This research is a descriptive analytical study with the method mixed method approach with sequential explanatory design. The number of samples used was 200 respondents. The results in this study indicate that the six MBCFPE criteria: leadership, strategic planning, focus on customers, measurement, analysis and knowledge management, focus on employees, process management have a positive and significant effect on BPJS patient satisfaction Batam Regional General Hospital means the better the variable results this will increase BPJS hospital patient satisfaction.
\end{abstract}

Keywords: Performance, Malcolm Baldrige Criteria for Performance Excellence, Satisfaction

\begin{abstract}
Abstrak
Rumah sakit merupakan salah satu bentuk organisasi yang bergerak di bidang pelayanan kesehatan. Pelayanan kesehatan inilah yang selalu dituntut agar selalu bertambah baik. Hal ini tidak mudah, karena terdapat persaingan yang semakin ketat. Salah satu faktor kunci keberhasilan dalam meningkatkan kinerja organisasi diawali dari kepuasan pasien Rumah Sakit itu sendiri. Penelitian ini menggunakan kriteria Malcolm Baldrige Criteria for Performance Excellence(MBCfPE). MBCfPE merupakan salah satu metode peningkatan kinerja organisasi secara keseluruhan dan terus-menerus.MBCfPE.Adapun tujuan dari penelitian ini adalah untuk menguji dan menganalisa mengenai pengaruh masing-masing keenam kriteria MBCFPE (kepemimpinan, perencanaan strategis, focus pada pelanggan, pengukuran,analisa dan manajemen pengetahuan, focus pada karyawan, manajemen proses.) terhadap kepuasan pasien BPJS kesehatan pada Rumah Sakit Umum Daerah Batam. Penelitian ini merupakan penelitian dengan deskriptif analisik dengan pendekatan metode mix method dengan sequential explanatory design. Jumlah jumlah sampel yang digunakan sebanyak 200 responden. Hasil dalam penelitian ini menunjukkan bahwa keenam kriteria MBCFPE :kepemimpinan, perencanaan strategis, focus pada pelanggan, pengukuran,analisa dan manajemen pengetahuan, focus pada karyawan, manajemen proses berpengaruh positif dan signifikan terhadap kepuasan pasien BPJS Rumah Sakit Umum Daerah Batam artinya semakin baik hasil variabel tersebut akan meningkatkan kepuasan pasien BPJS kesehatan rumah sakit.
\end{abstract}

Kata Kunci : Kinerja, Malcolm Baldrige Criteria for Performance Excellence, Kepuasan 


\section{PENDAHULUAN}

Kesehatan adalah kebutuhan yang sangat penting bagi manusia, dan merupakan modal utama dalam melakukan aktifitas sehari-hari. Untuk mewujudkan suatu masyarakat yang mempunyai derajat kesehatan yang tinggi, maka pelaksanaan pembangunan di sektor kesehatan menjadi prioritas. Pembangunan di sektor kesehatan meliputi memperbaiki dan memperbanyak sarana kesehatan, baik itu sarana kesehatan milik pemerintah maupun swasta.

Jaminan kesehatan Nasional (JKN) merupakan sistem jaminan kesehatan yang melindungi setiap warga negaranya dan diharapkan dapat dirasakan oleh masyarakat luas secara adil dan merata. Pelaksanaan Jaminan Kesehatan Nasional berdasarkan UU no. 24 tahun 2011, karena berdasarkan UU tersebut BPJS di tunjuk sebagai pelaksana JKN dan juga menggantikan lembaga jaminan sosialnya yang ada di Indonesia, yaitu PT Askes sebagai lembaga asuransi jaminan kesehatan dan PT Jamsostek sebagai lembaga asuransi jaminan ketenagakerjaan. Selanjutnya PT Askes berubah menjadi BPJS kesehatan pada awal tahun 2014 kemudian PT Jamsostek menjadi BPJS ketenagakerjaan. Pemerintah berharap dengan pelaksanaan BPJS dapat menjamin seluruh peserta memperoleh manfaat pemeliharaan kesehatan dan sebagai pelindung dalam memenuhi kebutuhan dasar kesehatan. Sejak pelaksanaan Jaminan Kesehatan Nasional tersebut sudah 162.780 .976 peserta yang terdaftar, yang tentunya akan terus bertambah dari hari ke hari, sampai akhirnya seluruh rakyat Indonesia diwajibkan untuk mendaftar sebagai peserta BPJS pada tahun 2019. Dalam operasionalnya BPJS kesehatan bekerja sama dengan FKTP (Fasilitas Kesehatan Tingkat Pertama) dan Rumah Sakit.

Rumah sakit perlu menerapkan sistem manajemen yang berorientasi pada kepuasan konsumen. Untuk itu rumah sakit harus menciptakan kinerja yang unggul. Kinerja yang unggul atau Performance Excellence merupakan salah satu faktor utama yang harus diupayakan oleh setiap organisasi untuk memenangkan persaingan global, begitu juga oleh perusahaan penyedia jasa pelayanan kesehatan.

Untuk menghasilkan mekanisme pengelolaan mutu yang bagus, perusahaan perlu menerapkan metode pengukuran yang efektif untuk dapat menganalisis dan menemukan dimensi mutu yang perlu diperbaiki atau ditingkatkan untuk mencapai mutu yang tinggi. Salah satu model pengukuran yang sudah dikenal luas dan terbukti secara efektif membantu keberhasilan penerapan sistem manajemen mutu adalah sistem Malcolm Baldrige National Quality Award. Malcolm Baldrige National Quality Awards (MBNQA) merupakan sistem manajemen yang sangat efektif untuk menghasilkan loyalitas pelanggan dan kinerja tinggi bila diterapkan dengan tepat (Hardiansyah, 2013)

Rumah sakit sebagai penyedia jasa pelayanan kesehatan harus dapat berkompetisi dalam era bisnis yang demikian itu. Salah satunya, rumah sakit dapat memberikan pelayanan kesehatan dengan peralatan yang modern, melihat bahwa segmen pasar bagi rumah sakit adalah seluruh lapisan masyarakat, tidak memandang golongan atau status masyarakat sehingga diharapkan semua masyarakat mendapatkan pelayanan rumah sakit yang memuaskan. Kepuasan pasien sebagai respon pelanggan terhadap ketidak sesuaian antara tingkat kepentingan sebelumnya dan kinerja katual yang dirasakan setelah pemakaian. Harapan berbanding lurus dengan keinginan pasien untuk bisa menikmati pelayanan dengan memuaskan. Apabila jasa yang diberikan sesuai yang diharapkan maka kualitas diinterpretasikan baik dan memuaskan demikian pula sebaiknya. (Abidin, 2016)

Sedangkan kinerja yang dirasakan adalah persepsi pasien terhadap apa yang ia terima setelah menggunakan jasa dari rumah sakit. Kepuasan pasien merupakan respons pemenuhan yang dianggap memuaskan pendapat lain tentang kepuasan konsumen adalah keseluruhan sikap yang ditujukan konsumen atas barang atau jasa setelah mereka memperoleh dan menggunakannya.

Rumah Sakit Umum Daerah Embun Fatima adalah satu-satunya rumah sakit negeri yang ada di Batam, memiliki program-program yang memberikan nilai tambah lebih bagi pelanggan, karyawan dan masyarakat serta mendukung pertumbuhan ekonomi daerah maupun nasional. Untuk menilai 
keberhasilan program-program yang dijalankan perlu dilakukan penilaian. Terutama didalam kepuasan pasien misalnya dalam pelayanan pasien BPJS yang tidak dibedakan dengan pasien umum serta kinerja pelayanan rumah sakit sangat mempengaruhi kepuasan pasien yang ada pada Rumah Sakit Umum Daerah. Berdasarkan latar belakang di atas, maka penulis tertarik melakukan penelitian dengan judul "Pengaruh Kinerja Pelayanan dengan pendekatan Malcolm Baldrige Terhadap Kepuasan Pasien BPJS Kesehatan Pada Rumah Sakit Umum Daerah Kota Batam"

\section{METODE}

Penelitian yang digunakan dalam penelitian ini adalah penelitian dengan deskriptif analisis dengan pendekatan kuantitatif, yaitu penelitian yang kemudian diolah dan dianalisis untuk diambil kesimpulan. Pengertian desain penelitian deskriptif menurut Sanusi (2011: 13) adalah desain penelitian yang disusun dalam rangka memberikan gambar secara sistematis tentang informasi ilmiah yang berasal dari subjek atau objek penelitian. Sedangkan pengertian kuantitatif menurut Sugiyono (2012: 7) dapat diartikan sebagai metode yang sudah cukup lama digunakan sehingga sudah mentradisi sebagai metode untuk penelitian, metode yang berlandaskan pada filsafat positivise, metode yang telah memenuhi kaidahkaidah ilmiah yaitu konkrit/empiris, obyektif, terukur, rasional dan sistematis, metode yang dapat ditemukan dan dikembangkan berbagai iptek baru, dan metode yang data penelitiannya berupa angkaangka dan analisis menggunakan statistik.

Pada penelitian ini, yang menjadi target populasi adalah semua pasien rawat jalan peserta BPJS kesehatan yang berobat pada saat peneliti datang ke lokasi pengambilan data. Keseluruhan populasi tidak mungkin diteliti karena keterbatasan waktu dan tenaga, oleh karena itu diambil sampel yang dapat mewakili semua populasi.

Menurut Adik wibowo (2006) sampel adalah dokumen dan orang, dan teori sampel yang dipakai adalah dengan menentukan orang dan dokumen yang dianggap sesuai dan penting contohnya pasien. ukuran sampel dalam penelitian harus memiliki jumlah sampel minimum lima kali jumlah pertanyaan yang di analisis. Misal pada penelitian ini terdapat 25 pertanyaan, maka minimum jumlah sampel yang dibutuhkan adalah 200 responden. kriteria sampel adalah pasien peserta BPJS kesehatan mandiri yang sedang berada di RSUD Batam.

\section{HASIL DAN PEMBAHASAN}

Dalam penelitian ini telah disebarkan sebanyak 200 kuesioner.Dimana responden penelitian ini adalah pasien BPJS Kesehatan RSUD Batam. Karakteristik yang dibahas dalam penelitian ini meliputi jenis kelamin, status, usia dan pendidikan. Reponden tersebut diolah menggunakan SPSS versi 20 untuk mendapatkan persentase karakteristik responden. Penyajian data mengenai identitas responden untuk memberikan gambaran tentang keadaan diri dari para responden. Dalam mengisi kuesioner, responden diminta memberikan identitas diri sebagai penunjang data.

\section{Uji Validitas Data}

Pengujian untuk membuktikan valid tidaknya item-item kuesioner dapat dilakukan dengan melihat angka koefisien korelasi product moment pearson. Dalam menentukan kelayakan suatu item yang digunakan biasanya dilakukan uji signifikasi koefisien korelasi pada tingkat 0,05 (Wibowo, 2012:37). 
Tabel 1. Hasil Uji Validitas Variabel X1 (Leadership)

\begin{tabular}{cccccc}
\hline No & Item & R Hitung & R Tabel & Signifikansi & Kesimpulan \\
\hline 1 & X1.1 & 0,777 & 0,1463 & 0,000 & Valid \\
\hline 2 & X1.2 & 0,844 & 0,1463 & 0,000 & Valid \\
\hline 3 & X1.3 & 0,859 & 0,1463 & 0,000 & Valid \\
\hline 4 & $X 1.4$ & 0,750 & 0,1463 & 0,000 & Valid \\
\hline 5 & X1.5 & 0,724 & 0,1463 & 0,000 & Valid \\
\hline 6 & X1.6 & 0,701 & 0,1463 & 0,000 & Valid \\
\hline
\end{tabular}

Sumber: Hasil penelitian yang diolah 2018

Tabel 2. Hasil Uji Validitas Variabel X2 (Strategic Planning)

\begin{tabular}{llllll}
\hline No & Item & R Hitung & R Tabel & Signifikansi & Kesimpulan \\
\hline 1 & X2.1 & 0,866 & 0,1463 & 0,000 & Valid \\
\hline 2 & X2.2 & 0,826 & 0,1463 & 0,000 & Valid \\
\hline 3 & X2.3 & 0,837 & 0,1463 & 0,000 & Valid \\
\hline
\end{tabular}

Sumber: Hasil penelitian yang diolah 2018

Tabel 3. Hasil Uji Validitas Variabel X3 (customer focused)

\begin{tabular}{llllll}
\hline No & Item & R Hitung & R Tabel & Signifikansi & Kesimpulan \\
\hline 1 & X3.1 & 0,825 & 0,1463 & 0,000 & Valid \\
\hline 2 & X3.2 & 0,884 & 0,1463 & 0,000 & Valid \\
\hline 3 & X3.3 & 0,860 & 0,1463 & 0,000 & Valid \\
\hline
\end{tabular}

Sumber: Hasil penelitian yang diolah 2018

Tabel 4. Hasil Uji Validitas Variabel X4 (Information and Analysis)

\begin{tabular}{llllll}
\hline No & Item & R Hitung & R Tabel & Signifikansi & Kesimpulan \\
\hline 1 & X4.1 & 0,841 & 0,1463 & 0,000 & Valid \\
\hline 2 & X4.2 & 0,774 & 0,1463 & 0,000 & Valid \\
\hline 3 & X4.3 & 0,769 & 0,1463 & 0,000 & Valid \\
\hline 4 & X4.4 & 0,876 & 0,1463 & 0,000 & Valid
\end{tabular}

Sumber: Hasil penelitian yang diolah 2018

Tabel 5. Hasil Uji Validitas Variabel X5 (Human Resources Focus)

\begin{tabular}{llllll}
\hline No & Item & R Hitung & R Tabel & Signifikansi & Kesimpulan \\
\hline 1 & X5.1 & 0,822 & 0,1463 & 0,000 & Valid \\
\hline 2 & X5.2 & 0,859 & 0,1463 & 0,000 & Valid \\
\hline 3 & X5.3 & 0,782 & 0,1463 & 0,000 & Valid \\
\hline 4 & X5.4 & 0,796 & 0,1463 & 0,000 & Valid \\
\hline 5 & X5.5 & 0,812 & 0,1463 & 0,000 & Valid \\
\hline 6 & X5.6 & 0,806 & 0,1463 & 0,000 & Valid \\
\hline 7 & X5.7 & 0,794 & 0,1463 & 0,000 & Valid \\
\hline
\end{tabular}

Sumber: Hasil penelitian yang diolah 2018

Tabel 6. Hasil Uji Validitas Variabel X6 (process management)

\begin{tabular}{llllll}
\hline No & Item & R Hitung & R Tabel & Signifikansi & Kesimpulan \\
\hline 1 & X6.1 & 0,830 & 0,1463 & 0,000 & Valid \\
\hline 2 & X6.2 & 0,875 & 0,1463 & 0,000 & Valid \\
\hline 3 & X6.3 & 0,846 & 0,1463 & 0,000 & Valid \\
\hline
\end{tabular}




\begin{tabular}{llllll}
\hline 4 & X6.4 & 0,878 & 0,1463 & 0,000 & Valid \\
\hline
\end{tabular}

Sumber: Hasil penelitian yang diolah 2018

Tabel 7. Hasil Uji Validitas Variabel Y (Kepuasan Kerja Karyawan)

\begin{tabular}{cccccc}
\hline No & Item & R Hitung & R Tabel & Signifikansi & Kesimpulan \\
\hline 1 & Y.1 & 0,753 & 0,1463 & 0,000 & Valid \\
\hline 2 & Y.2 & 0,791 & 0,1463 & 0,000 & Valid \\
\hline 3 & Y.3 & 0,889 & 0,1463 & 0,000 & Valid \\
\hline 4 & Y.4 & 0,798 & 0,1463 & 0,000 & Valid \\
\hline 5 & Y.5 & 0,797 & 0,1463 & 0,000 & Valid \\
\hline 6 & Y.6 & 0,795 & 0,1463 & 0,000 & Valid \\
\hline
\end{tabular}

Sumber: Hasil penelitian yang diolah 2018

Tebel 7.Hasil Uji Reliabilitas

\begin{tabular}{ccc}
\hline Variabel & Cronbach Alpha & Keterangan \\
\hline Leadership $(\mathrm{X} 1)$ & 0,901 & Reliabel \\
\hline Strategic planning $(\mathrm{X} 2)$ & 0,921 & Reliabel \\
\hline Customer focused $(\mathrm{X} 3)$ & 0,918 & Reliabel \\
\hline Information and analysis $(\mathrm{X} 4)$ & 0,910 & Reliabel \\
\hline Human resources focus $(\mathrm{X} 5)$ & 0,913 & Reliabel \\
\hline Process management $(\mathrm{X} 6)$ & 0,912 & Reliabel \\
\hline Kepuasan Kerja Karyawan $(\mathrm{Y})$ & 0,908 & Reliabel
\end{tabular}

Sumber: Hasil penelitian yang diolah 2018

Uji Kolmogorov-Smirnov

Tabel 8. Hasil Uji Kolmogorov-Smirnov

\begin{tabular}{|c|c|c|}
\hline \multicolumn{3}{|c|}{ One-Sample Kolmogorov-Smirnov Test } \\
\hline \multirow{2}{*}{\multicolumn{2}{|c|}{$\mathrm{N}$}} & $\begin{array}{l}\text { Standardized } \\
\text { Residual }\end{array}$ \\
\hline & & 200 \\
\hline Normal & Mean & 0 \\
\hline \multirow[t]{2}{*}{ Parameters $^{\mathrm{a}, \mathrm{b}}$} & Std. Deviation & ,98687033 \\
\hline & Absolute &, 148 \\
\hline Most Extreme & Positive &, 119 \\
\hline Differences & Negative &,- 148 \\
\hline \multicolumn{2}{|c|}{ Kolmogorov-Smirnov Z } & 1,597 \\
\hline \multicolumn{2}{|c|}{ Asymp. Sig. (2-tailed) } &, 112 \\
\hline
\end{tabular}

a. Test distribution is Normal.

b. Calculated from data.

Dari tabel diatas diperoleh nilai Kolmogorov Smirnov memiliki nilai Asymp.Sig (2-tailed) sebesar 0,112. Jika nilai Asymp.Sig lebih besar dari 0,05 maka distribusi data adalah normal. Jika nilai Asymp.Sig lebih kecil dari 0,05 maka distribusi data tidak normal. Maka dapat disimpulkan bahwa data diatas berdistribusi normal.

Uji Multikolinearitas 

ini :

Hasil pengujian multikolinearitas untuk masing-masing variabel dapat dilihat pada Tabel 9 di bawah

Tabel 9. Hasil Uji Multikolinearitas

Coefficients $^{\text {a }}$

\begin{tabular}{|c|c|c|c|c|}
\hline & Model & $\begin{array}{r}\text { Colline } \\
\text { Statis }\end{array}$ & $\begin{array}{l}\text { rity } \\
\text { cs }\end{array}$ & \\
\hline & & Tolerance & VIF & Kesimpulan \\
\hline & (Constant) & & & \\
\hline & Leadership & ,603 & 1,658 & $\begin{array}{c}\text { Tidak Terjadi } \\
\text { Multikoloniearitas }\end{array}$ \\
\hline & strategic planning & ,494 & 2,024 & $\begin{array}{c}\text { Tidak Terjadi } \\
\text { Multikoloniearitas }\end{array}$ \\
\hline 1 & customer focused & ,934 & 1,070 & $\begin{array}{c}\text { Tidak Terjadi } \\
\text { Multikoloniearitas }\end{array}$ \\
\hline & $\begin{array}{c}\text { information and } \\
\text { analysis }\end{array}$ & ,992 & 1,008 & $\begin{array}{c}\text { Tidak Terjadi } \\
\text { Multikoloniearitas }\end{array}$ \\
\hline & $\begin{array}{l}\text { human resources } \\
\text { focus }\end{array}$ & ,852 & 1,174 & $\begin{array}{c}\text { Tidak Terjadi } \\
\text { Multikoloniearitas }\end{array}$ \\
\hline & process management & 379 & 2,642 & $\begin{array}{c}\text { Tidak Terjadi } \\
\text { Multikoloniearitas }\end{array}$ \\
\hline
\end{tabular}

a. Dependent Variable: kepuasan pasien

Sumber : Hasil penelitian yang diolah 2018

Tabel 10 Hasil Uji Analisis Regresi Berganda

\begin{tabular}{|c|c|c|c|c|c|c|}
\hline \multicolumn{7}{|c|}{ Coefficients $^{\mathrm{a}}$} \\
\hline & Model & \multicolumn{2}{|c|}{$\begin{array}{l}\text { Unstandardized } \\
\text { Coefficients }\end{array}$} & \multirow{2}{*}{$\begin{array}{c}\text { Standardize } \\
\mathrm{d} \\
\text { Coefficient } \\
\mathrm{s} \\
\text { Beta }\end{array}$} & \multirow[t]{2}{*}{$\mathrm{t}$} & \multirow[t]{2}{*}{ Sig. } \\
\hline & & $B$ & Std Error & & & \\
\hline \multirow{7}{*}{1} & (Constant) & 3,140 & .753 & & 4.170 & .000 \\
\hline & Leadership & ,078 & ,027 &, 110 & 2,901 &, 004 \\
\hline & strategic planning & , 124 & ,055 & ,095 & 2,266 & ,025 \\
\hline & customer focused & ,092 & ,034 & ,081 & 2,673 &, 008 \\
\hline & $\begin{array}{l}\text { information and } \\
\text { analysis }\end{array}$ &, 050 & ,023 & ,064 & 2,170 & ,031 \\
\hline & $\begin{array}{l}\text { human resources } \\
\text { focus }\end{array}$ & ,062 & ,026 & ,076 & 2,378 & ,019 \\
\hline & $\begin{array}{c}\text { process } \\
\text { management }\end{array}$ & ,955 & ,061 & ,747 & 15,668 &, 000 \\
\hline
\end{tabular}

a. Dependent Variable: kepuasan pasien

Sumber: Hasil penelitian yang diolah 2018

Berdasarkan Tabel 10 di atas, dapat diketahui persamaan hasil uji analisis regresi berganda adalah sebagai berikut :

$Y^{2}=3,140+0,078 X_{1}+0,124 X_{2}+0,092 X_{3}+0,050 X_{4}+0,062 X_{5}+0,955 X_{6}$ 
Tabel 11. Koefisien Determinasi $\left(\mathrm{R}^{2}\right)$

Model Summary

\begin{tabular}{ccccc}
\hline Model & $\mathrm{R}$ & $\mathrm{R}$ Square & Adjusted R Square & $\begin{array}{c}\text { Std. Error of the } \\
\text { Estimate }\end{array}$ \\
\hline 1 &, $923^{\mathrm{a}}$ &, 853 &, 848 & 1,145 \\
\hline
\end{tabular}

a. Predictors: (Constant), process management, information and analysis , customer focused, human resources focus , leadership, strategic planning

Tabel 12. Hasil Uji t

\begin{tabular}{|c|c|c|c|c|c|c|}
\hline \multicolumn{7}{|c|}{ Coefficients $^{a}$} \\
\hline \multirow{2}{*}{\multicolumn{2}{|c|}{ Model }} & \multicolumn{2}{|c|}{ Unstandardized Coefficients } & \multirow{2}{*}{$\begin{array}{c}\begin{array}{c}\text { Standardized } \\
\text { Coefficients }\end{array} \\
\text { Beta } \\
\end{array}$} & \multirow[b]{2}{*}{$\mathrm{t}$} & \multirow[b]{2}{*}{ Sig. } \\
\hline & & $\mathrm{B}$ & Std. Error & & & \\
\hline \multirow[t]{7}{*}{1} & (Constant) & 3,140 &, 753 & & 4,170 &, 000 \\
\hline & leadership & ,078 &, 027 & , 110 & 2,901 &, 004 \\
\hline & strategic planning & ,124 &, 055 &, 095 & 2,266 &, 025 \\
\hline & customer focused & 092 &, 034 &, 081 & 2,673 &, 008 \\
\hline & information and analysis &, 050 &, 023 &, 064 & 2,170 &, 031 \\
\hline & human resources focus &, 062 &, 026 &, 076 & 2,378 &, 019 \\
\hline & process management & ,955 &, 061 &, 747 & 15,668 &, 000 \\
\hline
\end{tabular}

a. Dependent variable: kepuasan pasien

Berdasarkan hasil pengujian dalam penelitian ini dapat diketahui bahwa variabel kepuasan pasien rumah sakit Umum Daerah Batam dapat dijelaskan oleh enam kireteria MBCfPE, yaitu leadership, strategic planning, customer focused, information and analysis, human resources focus, dan process management, hasil ini sesuai dengan hasil hipotesis yang diajukan. Dari hasil determinasi diperoleh nilai Adjusted $R$ Square sebesar 0,848. Hasil ini menunjukkan bahwa leadership, strategic planning, customer focused, information and analysis, human resources focus, dan process management mampu menjelaskan sebesar $84,8 \%$ terhadap variabel kepuasan pasien pada rumah sakit Umum Daerah Batam. Sedangkan sisanya $15,2 \%$ dijelaskan oleh variabel lain yang tidak dimasukkan dalam penelitian ini.

\section{KESIMPULAN}

1. Terdapat pengaruh antara leadership terhadap kepuasan pasien pada Rumah Sakit Umum Daerah Batam.

2. Terdapat pengaruh antara strategic planning kepuasan pasien pada Rumah Sakit Umum Daerah Batam.

3. Terdapat pengaruh antara customer focused kepuasan pasien pada Rumah Sakit Umum Daerah Batam.

4. Terdapat pengaruh antara information and analysis terhadap kepuasan pasien pada Rumah Sakit Umum Daerah Batam. 
5. Terdapat pengaruh antara human resources focus terhadap kepuasan pasien pada Rumah Sakit Umum Daerah Batam.

6. Terdapat pengaruh antara human resources focus terhadap kepuasan pasien pada Rumah Sakit Umum Daerah Batam.

\section{DAFTAR PUSTAKA}

[1].Abidin. (2016). Pengaruh Kualitas Pelayanan Bpjs Kesehatan Terhadap Kepuasan Pasien Di Puskesmas Cempae Kota Parepare. Jurnal Mkmi, 12(2), $70-75$. Https://Doi.Org/10.30597/Mkmi.V12i2.922

[2].Arijanto, S., \& Harsono, A. R. (2010). Pengukuran Kinerja Fakultas Di Perguruan Tinggi " $X$ " Menggunakan Pendekatan Malcolm Baldrige Criteria For Performance Excellence (Education Criteria). Proceeding Seminar Nasional Iv Manajemen Dan Rekayasa Kualitas.

[3].Eka, Eka. (2017). Kualitas Pelayanan Publik Di Kantor Camat Rumbai Pesisir. Jurnal Niara, 9(2), 109-114. Https://Doi.Org/10.31849/Nia.V9i2.2104

[4].Hardiansyah. (2013). Analisis Pengaruh Pendekatan Malcolm Baldrige Criteria For Performance Excellence Terhadap Kinerja Pt Trakindo Utama Cabang Medan.

[5].Kunst, Paul, \& Lemink, J. (2000). No Titlequality Management And Business Performance In Hospital: A Research For Success Parameter. Taylor \& Francis Ltd.

[6].Lee, \& Sunhee. (2002). Assessing The Faktor Influencing Continuous Quality Improvement Implementation, Experience In Korean Hospital, International Journal For Quality In Health Care. Oxford University Press.

[7].Davis, Robert A. \& Stading, Gary L. (2005). Linking Firm Performance To The Malcolm Baldrige National Quality Award Implementation Effort Using Multriattribute Utility Theory. Journal Of Southwest Texas State University And University Of Houston, Volume 31 Number 3.

[8].Cazzel, Brian \& Ulmer, Jeffrey M. (2009). A Closer Look At Malcolm Baldrige National Quality Award Winners In The Manufacturing Category. Journal Of University Of Central Missouri, Volume 4, Issue 1.

[9].Giunta, Et.Al. (2006). The Significance Of The Malcolm Baldrige National Quality Award (Mbnqa) As Key Competencies For Human Resource Business Professionals. Journal Of Capella University

[10].Imbalo S. Pohan 2006. Jaminan Mutu Layanan Kesehatan. Jakarta: Egc

[11].Mulyadi. 2007. Sistem Perencanaan Dan Pengendalian Manajemen. Jakarta: Salemba Empat

[12].Peraturan Badan Penyelenggara Jaminan Sosial Kesehatan Nomor 1 Tahun 2014 Tentang Penyelenggaraan Jaminan Kesehatan 
[13].Peraturan Menteri Kesehatan Republik Indonesia Nomor 71 Tahun 2013 Tentang Pelayanan Kesehatan Pada Jaminan Kesehatan Nasional

[14].Rivai Veihzal, Dan Fawzi Ahmad. 2005. Performance Appraisal. Pt. Raja Grafindo Persada: Jakarta

[15].Saputra, T. (2018). Capaian Pelayanan Kesehatan Dasar Di Kota Pekanbaru. Jurnal Ilmu Sosial, 16(1), 47-57.

[16].Saputra, Trio, Marlinda, Pebriana, \& Sufi, Wasiah. (2018). Pengaruh Gaya Kepemimpinan Transformasional Terhadap Efektifitas Kinerja Pegawai Puskesmas Rawat Inap Sidomulyo Barat Kota Pekanbaru. Jurnal Niara, 9(1), 10-17. Https://Doi.Org/10.31849/Nia.V9i1.2012

[17].Soekidjo Notoatmodjo 2005. Metodologi Penelitian Kesehatan. Jakarta : Rineka Cipta.

[18].Supranto,J 2006. Pengukuran Tingkat Kepuasan Pelanggan : Untuk Menaikan Pangsa Pasar. Jakarta : Rineka Cipta.

[19].Sugiyono. 2008. Metode Penelitian Bisnis. Cetakan Keduabelas, Alfabeta: Bandung.

[20].Undang-Undang Republik Indonesia Nomor 24 Tahun 2011 Tentang Badan Penyelenggara Jaminan Sosial (Bpjs).

[21].Wibowo, Adik. 2014. Kesehatan Masyarakat Indonesia. Pt. Rajagrafindo Persada. Jakarta.

[22].Wibowo. 2007. Manajemen Kinerja. Pt. Raja Grafindo Parsada: Jakarta 